\title{
Effect of Burnishing Process on Behavior of Engineering Materials- A Review
}

\author{
${ }^{1}$ Prof. Ghodake A. P., ${ }^{2}$ Prof. Rakhade R.D., ${ }^{3}$ Prof. Maheshwari A.S. \\ ${ }^{1,2}$ Department of Mechanical Engineering, SND COE \& RC Yeola, Nasik, India. \\ ${ }^{3}$ Department of Mechanical Engineering, Sandip foundation's Sandip Institute of Technology \& RC, Nasik, \\ India,
}

\begin{abstract}
Quality of Surface is an important factor to decide the performance of a manufactured product. Surface quality affect product performance like assembly fit, aesthetic appeal that a customer might have for product. The nominal surfaces of the object are represented by perfect straight line, perfect circles, round holes, straightness and absolute perpendicularity $A$ variety of processes are used to make the designed parts. The characteristics of surfaces includes surface texture, surface integrity which is always related with manufacturing processes for maintain quality of surfaces. For better quality surface finish the main factor is surface roughness. The lower value of roughness gives higher surface finish for the manufactured product. Now in present scenario different processes like grinding, honing, super finishing, polishing, burnishing etc are used to reduce the value of surface roughness. Burnishing is one of the processes which majorly affect the surface roughness. In conventional machining processes the tensile residual stresses are induced on the surface of material, which reduces the fatigue strength of material, this can be prevented by inducing residual compressive stresses on the surface of material. Burnishing is a cold working process in which initial asperities are compressed beyond yield strength against load. The surface of the material is progressively compressed, then plasticized as resultant stresses reach a steady maximum value and finally wiped a superfine finish. The highly finished processes find the application in aerospace and aircraft industry.
\end{abstract}

Key words: Burnishing, Methods used, Mechanical properties, Surface Roughness

\section{Introduction}

Burnishing is a cold working process in which plastic deformation occurs by applying a pressure through a ball or roller on metallic surfaces. It is a finishing and strengthening process. Improvements in surface finish, surface hardness, wear resistance, fatigue resistance, yield and tensile strength and corrosion resistance can be achieved by the application of this process.

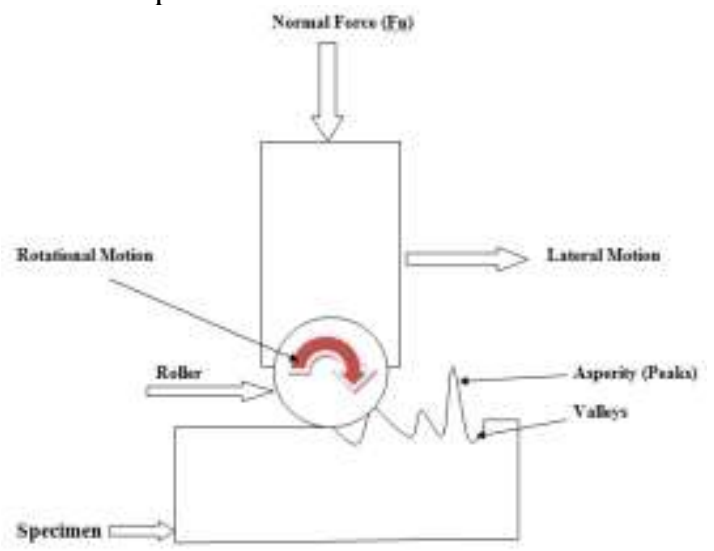

Fig.1 Schematic illustration of burnishing mechanism

Burnishing is one of the important finishing operations carried out generally to enhance the fatigue resistance characteristics of components. Burnishing tools are used to impart a gloss or fine surface finish, often in processes that involve the cold working of metal surfaces. Burnishing tools are also used for the sizing and finishing of surfaces. A burnishing tool develops a finished surface on turned or bored metal surface by performing a continuous planetary rotation of hardened rolls. The rotation of the rolls increases the yield point of the soft portion of the metal surface at the point of contact. The material in the peaks gets plastic deformation and it is filled up in the valleys, as shown in the fig. 1 the point of contact results in the deformation of the metal surface to generate a finished metal surface. There are many types of burnishing tools. Burnishing is not a metal cutting process. In burnishing process, chips are not produced. It is essentially a cold forming process, in 
which the metal near a machined surface is displaced from protrusions to fill the depressions. Due to the work hardening of the surface during burnishing, there will be a hardened layer on the surface and it is expected to increase the fatigue resistance of the component. Apart from improvement in surface finish and fatigue strength, burnishing process imparts improved wear and corrosion resistance.

In today's manufacturing industry, special attention is given to dimensional accuracy and surface finish. Thus, measuring and characterizing the surface roughness can be considered as the predictor of the machining performance. Burnishing is a process that leads to an accurate change in the surface roughness of the work piece by a minor amount of plastic deformation. In burnishing process, the metal on the surface of the work piece is redistributed without material loss. Besides producing a good surface finish, the burnishing process has additional advantages such as securing increased hardness, corrosion resistance and fatigue life as result of the produced compressive residual stress. [9]

\subsection{Roughness:}

\section{Parameters that affect surface finish.}

It consists of relatively closely-spaced or fine surface irregularities, mainly in the form of feed marks left by the cutting tool on the machined surface. The mean height or depth of irregularities is measured over a relatively small length called the roughness sampling length.

\subsection{Waviness:}

It consists of all surface irregularities whose spacing is greater than the roughness sampling length (about $1 \mathrm{~mm}$ ). Waviness may be caused by vibration, chatter, and tool and work piece deflections due to cutting loads and cutting temperature.

\subsection{Lay:}

It denotes the predominant direction of the surface irregularities. The lay is usually specified with respect to an edge called the reference edge of the work piece. The lay depends upon the orientation of the work piece and the cutting tool on the machine as well as the nature of the relative motion between the two.

\subsection{Surface Flaws:}

Flaws could be due to inherent defects, such as inclusions, cracks, blow-holes, etc. in the work piece that get exposed on machining, or they could arise from the machining process.

\section{The Typical Ranges of Surface Finish Obtained By Various Surface Finish Methods}

Table.1Typical Ranges of surface Roughness, Ra, $\boldsymbol{\mu n}$
\begin{tabular}{|c|c|}
\hline Process & Average application \\
\hline Grinding & 0.1 to 1.6 \\
\hline Lapping & 0.05 to 0.4 \\
\hline Honing & 0.1 to 0.8 \\
\hline Buffing & 0.05 to 0.5 \\
\hline Super finishing & 0.05 to 0.2 \\
\hline Burnishing & 0.2 to 0.8 \\
\hline
\end{tabular}

\section{Methods Used in for optimization of burnishing parameters.}

There are several methods used to predict optimized values of burnishing process. Many researchers studied and worked on the optimization methods.

Fang-Jung Shiou et al used Taguchi L18 Orthogonal array technique and ANOVA to investigate the surface roughness value. Best on their results The Vickers hardness scale of the tested specimen was improved from about 338 to 480 after ball-burnishing process. The hardened layer thickness was about $30 \mu \mathrm{m}$. By applying the optimal burnishing parameters for plane burnishing to the surface finish of the freeform surface mold cavity, the surface roughness improvement of the injection part on plane surface was about $62.9 \%$ and that on freeform surface was about $77.8 \%$.[2]

U.M. Shirsat et al studied the parametric analysis of combined turning and ball burnishing process they used factorial design $\left(2^{3}\right) .2^{3}$ factorial designs represent eight-experiments, where the experimental points are located at the vertices of a cube shown in Fig. 2. Four experiments represent an added centre-point to the cube, repeated four times to estimate the pure error. The complete design consists of 12 experiments divided into two blocks, each block containing six experiments and one combined block is considered (trial nos 1 to 12)8, 9. This method classifies and identifies the parameters to three different levels (viz. low, center and high). In this experimentation, twelve tests were carried out at these levels. 


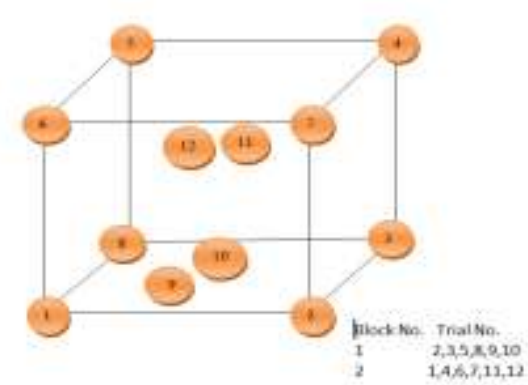

Fig.2. Composite Design [3]

For each block the model equations for surface roughness and the surface hardness are obtained by using the analysis of variance technique (ANOVA) and regression coefficient. They develop a mathematical model for obtaining values of surface roughness. The functional relationship between response (surface roughness) of the burnishing operation and the investigated independent variables can be represented by the following equation $\mathbf{R a}=\mathbf{K} * \mathbf{F}^{\mathrm{a} * \mathbf{V}^{\mathrm{b}} * \mathbf{S}^{\mathrm{c}} \ldots}$ (1)

Where Ra is surface roughness $(\mu \mathrm{m}), \mathrm{F}, \mathrm{V}$ and $\mathrm{S}$ are the force $(\mathrm{kgf})$, speed $(\mathrm{m} / \mathrm{min})$ and feed $(\mathrm{min} / \mathrm{rev})$. [3]

J.N. Malleswara Rao et al worked on finite element approach for the prediction of Residual stresses in aluminum work pieces Produced by roller burnishing. In this work using numerical approach, compressive residual stress is calculated. Roughness is considered as a triangular asperity in this numerical approach. Before burnishing, the height of the triangle is considered as the roughness of the work piece. The normal force is acting on the peak of the asperity. Fig. 3 represents the triangular model for numerical approach. The depth of deformed layer depends on the yield strength of the material ( $\sigma \mathrm{y})$, normal load $(\mathrm{Fn})$, and the asperity angle $(\alpha)$

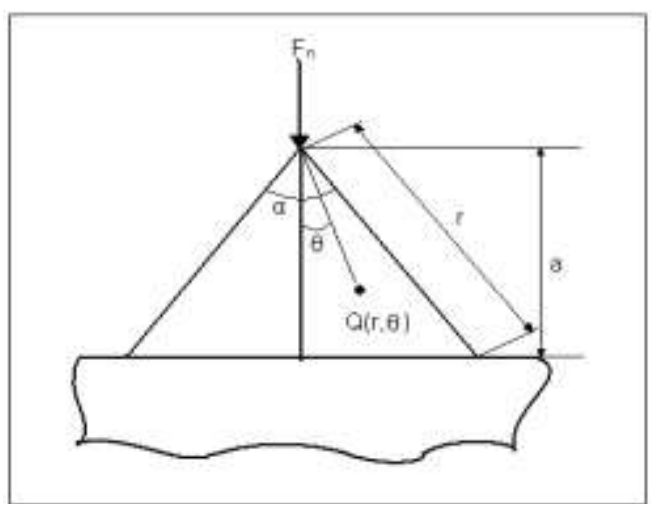

Fig. 3 coordinates of a point $Q(r, \theta)$ within a triangular asperity [19]

Commercially available FEA package ANSYS- 12 is used to simulate the analysis process. The burnishing process is modeled as 2 D FEA and the surface roughness is considered as a triangular asperity with included angle of $\alpha$ equal to $80^{\circ}$. The height of the triangular asperity is considered as the surface roughness before burnishing which is taken as ' $a$ '. [11]

N.S.M. EL-Tayeb et al worked on Prediction of Burnishing Surface Integrity using Radial Basis Function. They used artificial neural network (ANN) and radial basic function (RBF) techniques to predict value of surface roughness. Artificial neural networks are computing elements, which are based on the structure and function of the biological neurons. These networks have nodes or neurons, which are described by difference or differential equations. The nodes are interconnected layer-wise or intra-connected among themselves. Each node in the successive layer receives the inner product of synaptic weights with the outputs of the nodes in the previous layer when the vectors are binary or bipolar, hard-limiting non-linearity is used. When the vectors are analog, a squashed function is used. [12]

Radial Basis Functions are capable of producing approximations to an unknown function ' $\mathrm{f}$ ' from a set of input data abscissa. The approximation is produced by passing an input point through a set of basic functions, each of which contains one of the RBF centres, multiplying the result of each function by a coefficient and then summing them linearly. 


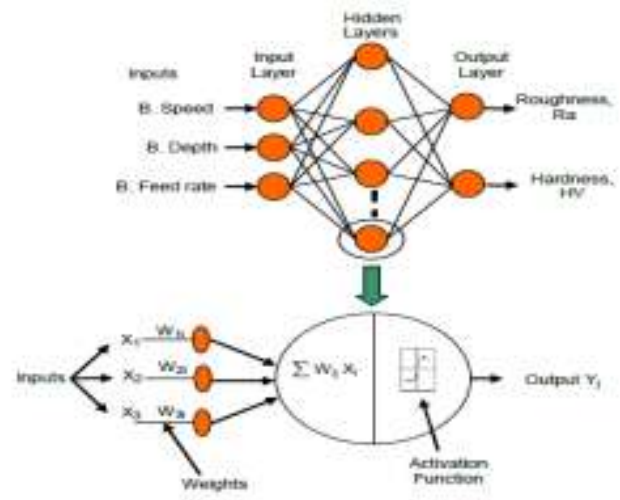

Fig. 4.Configuration of ANN showing details of relationship between input and output of one neuron. [12] In this work speed, depth and feed rate are taken as input parameters for the process while hardness and roughness are the output parameters.

\subsection{Ductility}

\section{Improved Mechanical Properties of Materials}

Fathi Gharbi Worked on aluminum 1050A rolled sheet for improvement of ductility by a newly designed ball burnishing tool device. It was found that the burnished surface had $48 \%$ improvement in ductility as compared with unfurnished specimen. When the specimen is burnished with burnishing conditions of $200 \mathrm{~N}, 400 \mathrm{rpm}$, and $0.1 \mathrm{~mm} / \mathrm{rev}$. In this optimum case, the yield strength, ultimate tensile strength, energy, and percent elongation at fracture for aluminum 1050A were 108.2 MPa, $125.16 \mathrm{MPa}, 21.01 \mathrm{~J}$, and $12.94 \%$, respectively. [15]In this case, the burnished specimen under the optimal conditions resists tensile well and its plasticity increases and as a result of this the ductility in the material shows improvement.

Khalid. S. Rababa et al, studied Effect of roller burnishing on mechanical behavior and surface quality of $\mathrm{O}_{1}$ Alloy steel, it was seen that there was a slight increase in ductility at $105 \mathrm{~N}$ force but there was a 76.6, 103.3, $113.3 \%$ increasing ductility at $140,175,210 \mathrm{~N}$ burnishing force. [19]

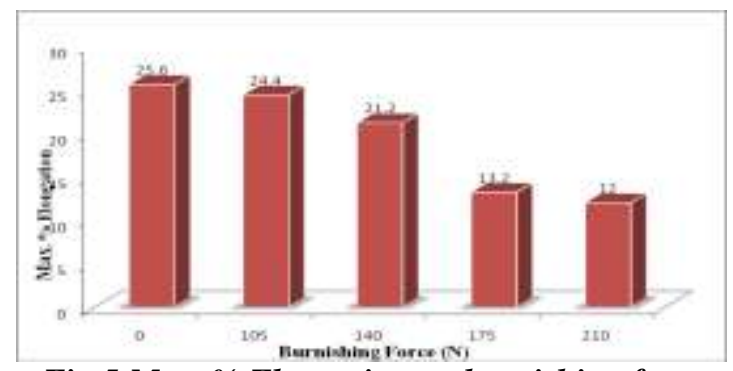

Fig.5.Max. \% Elongation vs. burnishing force

\subsection{Residual stress}

Fathi Gharbi et al studied the distribution of compressive residual stresses by ball burnishing process. It was observed that the residual stresses are compressive with low values between 0 and $-45 \mathrm{MPa}$. It is observed that in the feed direction, burnishing normal load has an influence on the affected depth corresponding to the optimum value of the residual stress $\sigma_{\mathrm{xx}}$, When the normal load increases from 100 to $200 \mathrm{~N}$ for the same ball diameter $(10 \mathrm{~mm})$, the affected depth increases from 40 to $110 \mu \mathrm{m}$, respectively, for an optimum value of $\sigma_{\mathrm{xx}}$ 30 and $-45 \mathrm{MPa}$, at $110 \mu \mathrm{m}$ and the optimum value of the residual stress $\sigma_{\mathrm{yy}}$ is Equal to -30 MPa.[15]
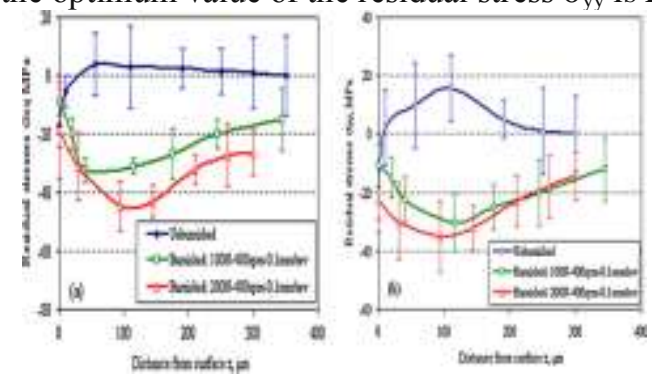

Fig.6 Residual stress profiles measured from surface: in the feed direction, $\sigma_{x x}(a)$, and in the cross-feed direction, $\sigma_{\mathrm{yy}}(b)[15]$ 
W Bouzid Sai et al worked on Finite element modeling of burnishing of AISI 1042 steel. In this case, to calculate the residual stresses in the feed perpendicular direction, the applied force by the tool on the machined surface $F$ increases from 0 to $150 \mathrm{~N}$ and then decreases to 0 again.
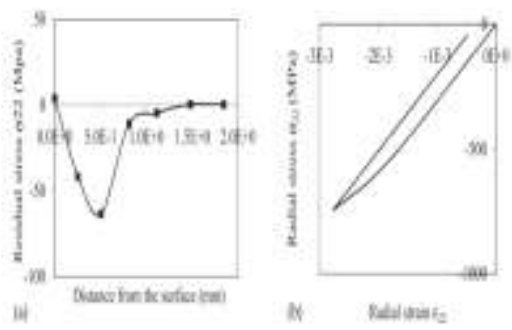

Fig. 7 residual stresses in the work piece [14]

Fig. 7 a shows the residual stress variation with the distance from burnished surface in the work piece, whereas Fig. 7 b gives a typical residual stress strain loop at node in which the residual stress takes the highest value. It appears clearly that the residual stress level is very low compared to experimental values [14].

J.N. Malleswara Rao, et al worked on Finite element Approach for the prediction of residual stresses in aluminum work piece produced by roller burnishing. It was seen that with increasing burnishing force the compressive stresses are induced in the material. [11]

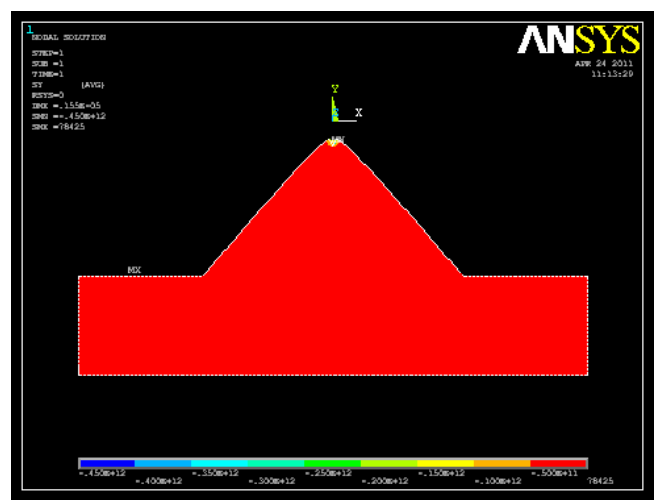

Fig. 8 Residual Stress distribution in Aluminum work piece [11]

It was also observed that the surface roughness value decreases due to deformation of surface irregularities.

\subsection{Tensile strength}

Fathi Gharbi et al studied the effect of ball burnishing process on tensile properties of material.

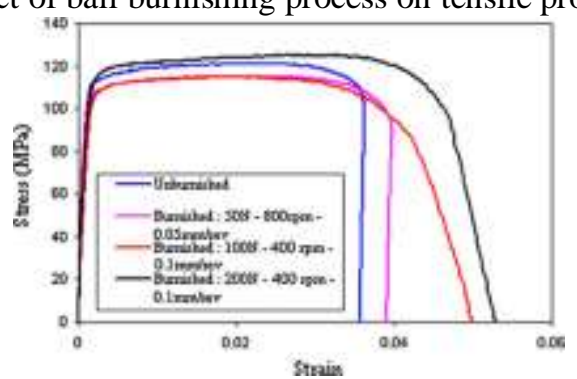

Fig. 9 Stress-strain curves of tensile tests for burnished and unburnished specimens.[17]

It was seen that the tensile test curves for cold-rolled aluminum 1050A for different burnishing conditions are illustrated in Fig. 9. As shown in Fig. 9, burnishing aluminum 1050A plates can have a significant effect on its stress- strain behavior. The stress-strain behavior for aluminum 1050A remains more or less constant in the plastic zone. Depending on the burnishing force, the yield strength and the ultimate tensile strength may decrease or increase as compared with the unburnished condition. Fig.9 also shows that the plasticity increases with no increase in the stress. Both the energy and percent elongation at fracture increase with burnishing. [17] Khalid. S. Rababa et al, studied Effect of roller burnishing on mechanical behavior and surface quality of $\mathrm{O}_{1}$ Alloy steel, it was seen that It can be seen from Fig. 15that by increasing the burnishing force (BF), UTS will increased until burnishing force reaches $(105 \mathrm{~N})$. 


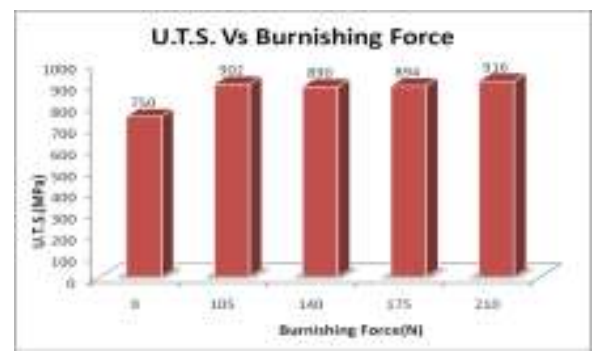

Fig.10.U.T.S. (MPa) vs. burnishing force (N)

At (105 to $175 \mathrm{~N})$ the BF has approximately the same effect, continuing increasing of BF the UTS will again increased until it reaches $(916 \mathrm{MPa})$ at $(210 \mathrm{~N})$ of $\mathrm{BF}$, but approximately all the BF resulted of about $22.1 \%) \cdot[19]$

\subsection{Hardness}

Adel Mahmood Hassan studied the effect of ball and roller burnishing on the surface roughness and hardness of some non ferrous metal. It was seen that the surface hardness of a material is increased with increase in burnishing force and number of burnishing tool passes. [1]

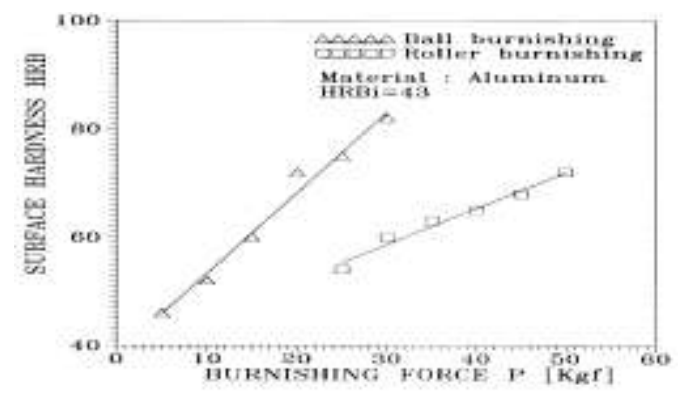

Fig.11The effect of burnishing force on surface hardness of aluminum [1]

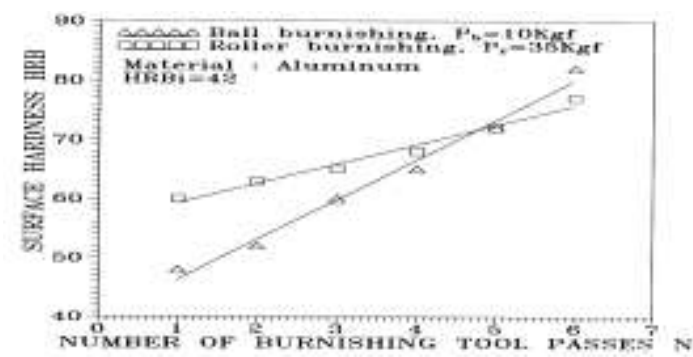

Fig.12 The effect of the number of burnishing tool passes on surface hardness of aluminum [1]

U.M. Shirsat et al worked on Parametric Analysis of combined turning and ball burnishing process. It was seen that the micro hardness increased with force up to certain extent only.

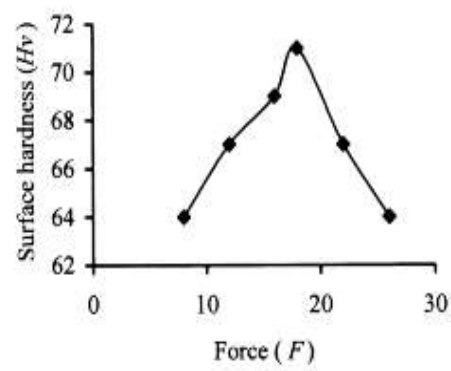

Fig.13 force verses hardness [3]

It was observed that the combine turning and ball burnishing gives maximum reduction in surface roughness.

F. Gharbi et al worked on Effect of ball burnishing process on the surface quality and microstructure properties of AISI 1010 steel plates. Based on their work it is observed that surface hardness increases with increasing burnishing force and number of burnishing tool passes. [8] 

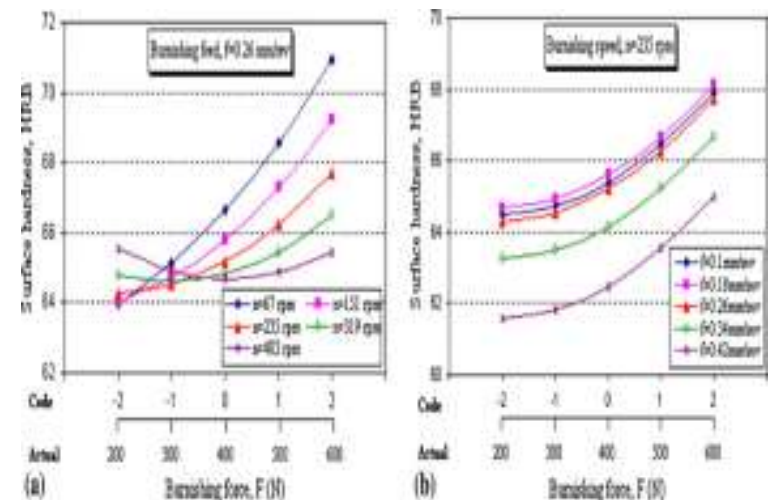

Fig.23 Effect of burnishing force on surface hardness: (a) at different speeds (rpm) and (b) at different feeds $(\mathrm{mm} / \mathrm{rev})$

It was also observed that speed and feed affect the surface hardness of steel plates.
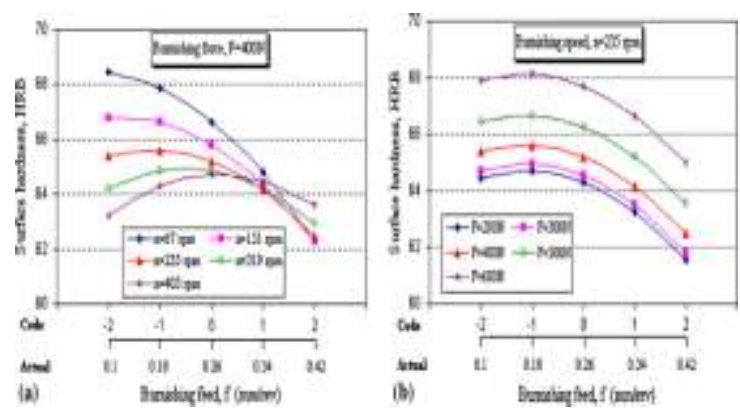

Fig.14 Effect of burnishing feed on surface hardness: (a) at different speeds (rpm) and (b) at different forces $(N)$

Malleswara Rao J.N et al studied the effect of roller burnishing on surface hardness and surface roughness on mild steel specimen, based on the works it was observed that the surface hardness increases with increasing burnishing force. This is mainly due to increased plastic deformation of micro irregularities with high burnishing force.[20]

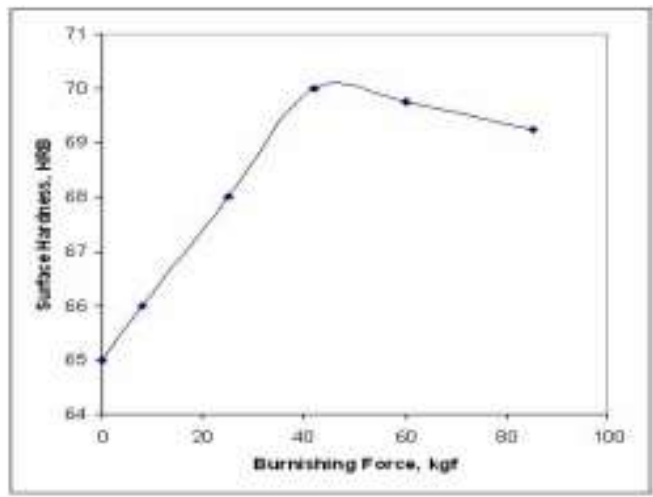

Fig.15 burnishing force verses surface hardness. [20]

\subsection{Wear resistance}

K. O. Low et al Studied Tribological effect of polymer surface modification through plastic deformation. It is observed that wear rate depends on burnishing force and burnishing speed. [21] 


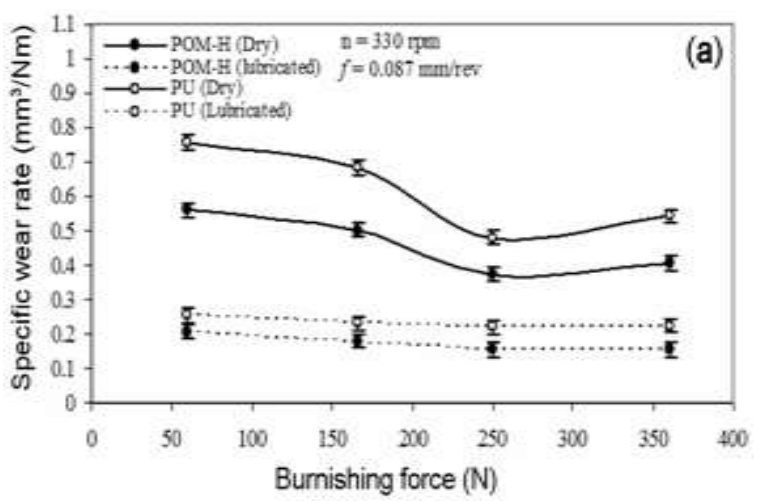

Fig.16 burnishing force verses wear rate

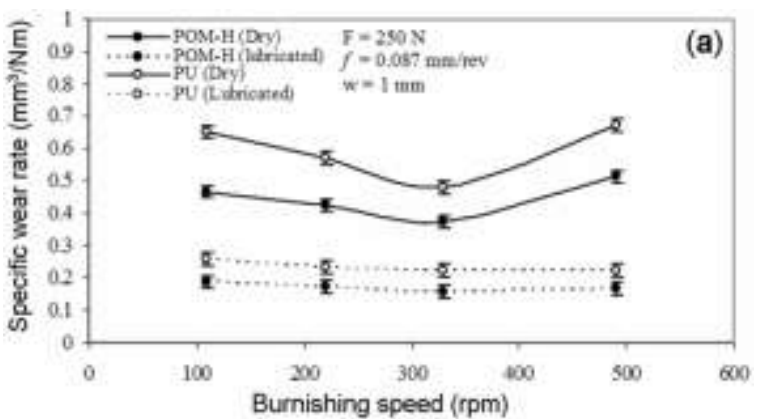

Fig.17 burnishing Speed verses wear rate [21]

6.1 Mild Steel

\section{Effect of burnishing process on engineering materials.}

Malleswara Rao J. $\mathbf{N}$ et al studied the effect of roller burnishing on surface hardness and surface roughness on mild steel specimen.

Basedontheirstudyitwasseenthatthe surface hardness of mild steel specimensincreases with increase in the burnis hing force up to $42 \mathrm{kgf.Further}$ increase of burnishing force results in the decrease of surface hardness on mild s eel specimens.The maximum surface hardness obtained is $70 \mathrm{HRB}$ [20]

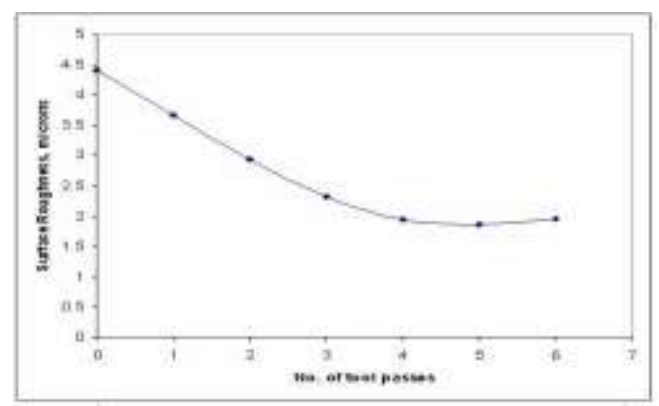

Fig 18 No. of passes verses surface roughness

Maximum reduction in surface roughness is observed in first five passes on mild steel by Roller burnishing operation. [20]

\section{2 $\mathrm{O}_{1}$ Alloy Steel}

Khalid. S. Rababa et al studied the Effect of roller burnishing on mechanical behavior and surface quality of $\mathrm{O}_{1}$ Alloy steel. Based on their study it was observed that the stress of material has been increased of about $150 \mathrm{MPa}, \mathrm{RB}$ has a positive effect on the surface roughness of $\mathrm{O} 1$ alloy steel. 


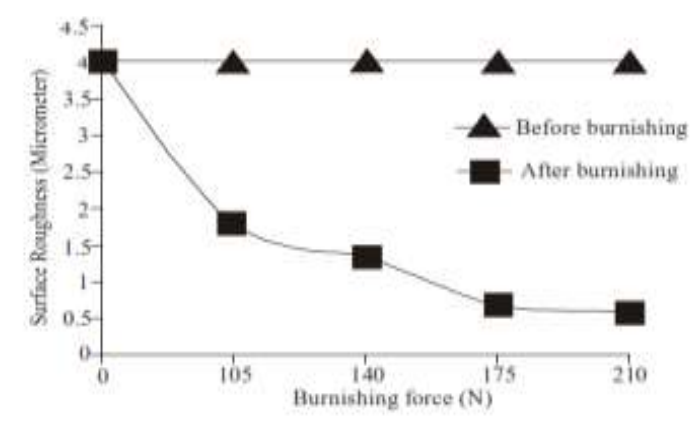

Fig.19 burnishing force verses roughness [19]

The surface roughness decreased with increasing burnishing force.

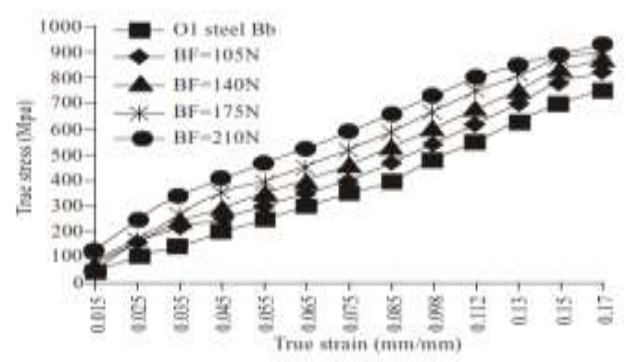

Fig. 20 true strain verses true stress

The improvement percentage on the surface quality was $12.5 \%$, Roller Burnishing (RB) has an effect on the ultimate tensile strength, the UTS has been increased by $166 \mathrm{MPa}$, RB has an effect on ductility of material; the percentage elongation of material has been increased of $13.6 \% \mathrm{RB}$ has an effect on cross sectional area, the reduction of cross sectional area has been increased of $1.8 \%$ [19]

\subsection{AISI 1042 Steel}

W Bouzid Sai et al worked on Finite element modeling of burnishing of AISI 1042 steel. Based on their work it was predicted that Good correlation was found based on roughness experimental results. For the range of feed, roughness results agree well qualitatively and quantitatively with results found by using Hertz contact theory. [14]

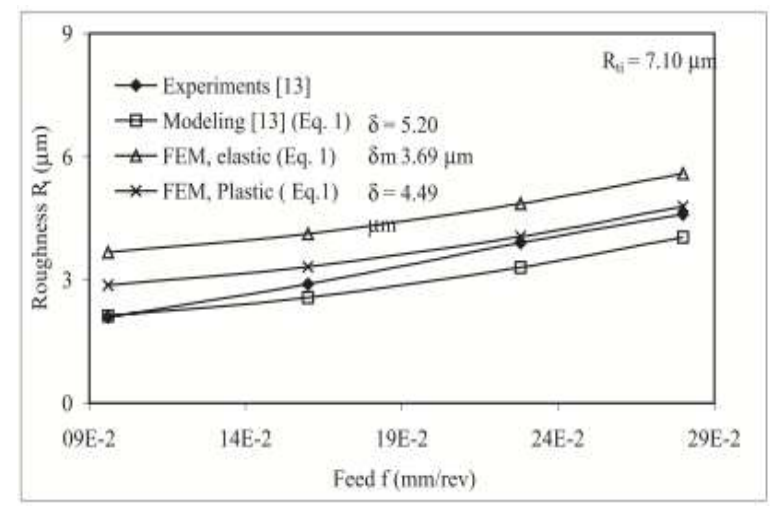

Fig. 21 Feed Verses roughness [14]

\subsection{Heat treated steel and Inconel 718 mild}

L.N. Lopez De Lacalle et al worked on the effect of ball burnishing on heat treated steel and inconel 718 milled surface. Based on their work it was observed that the hydrostatic ball burnishing process is a relatively new enhanced surface treatment on free-form parts, previously obtained by milling. 


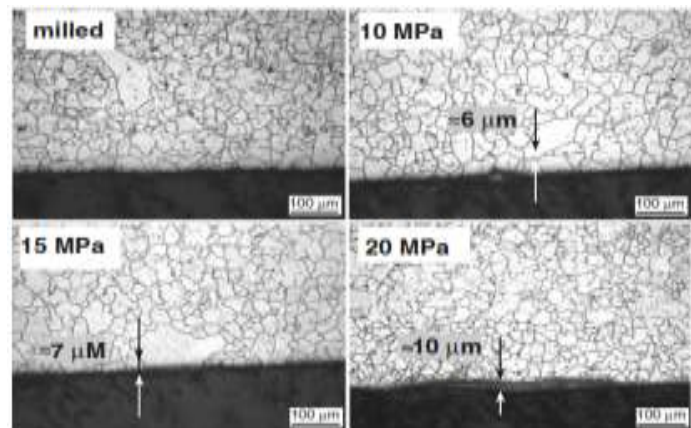

Fig. 22 Microstructure of surface (cross-sectional view), only machined and after ball burnishing at 10, 15 and $20 \mathrm{MPa}$. [5]

In fig. 22 it is observed that maximum pressure $20 \mathrm{MPa}$ leads to the highest quality improvement in the steels, but not in the Inconel case. In this ductile material high pressures induce the appearance of grooves on burnished surface. The best results are with pressures from 10 to $15 \mathrm{MPa}$ [5]

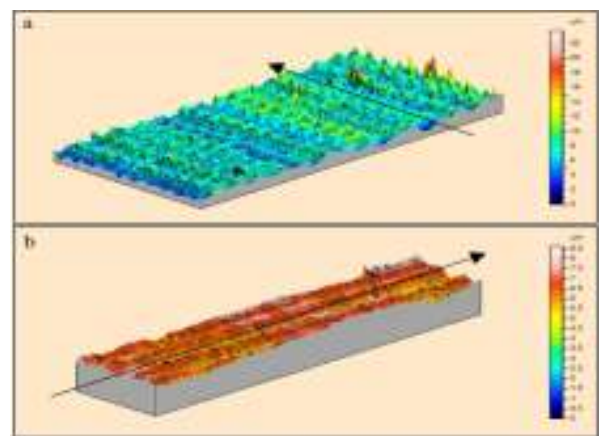

Fig. 23 before burnishing (a) and after burnishing (b) [7]

It was seen that the surface roughness reduces after burnishing process.

\subsection{Aluminum Alloy.}

Ugur Esme et al worked on Use of grey based taguchi method in ball Burnishing process for the optimization of Surface roughness and micro hardness of AA 7075 aluminum alloy. Based on their work it was predicted that the burnishing force has maximum contribution of affecting the surface roughness.

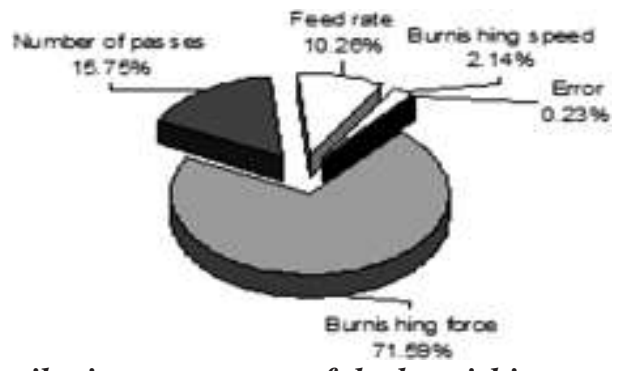

Fig. 24 Contribution percentage of the burnishing parameters [17]

The contribution of burnishing force and no. of tool passes is more which $71.59 \%$ for force and $15.75 \%$ for no. of passes.

\subsection{Aluminum}

N.S.M. El Tayeb et al worked on Influence of roller burnishing contact width and burnishing orientation on surface quality and triblogical behavior of Aluminum 6061 Based on their work it was predicted that the Optimum ranges of burnishing speed and force are identified to be $250-420 \mathrm{rpm}$ for $1 \mathrm{~mm}$ roller contact width. [22]

Burnishing force above $220 \mathrm{~N}$ is capable of decreasing the surface roughness by $35 \%$. Below this limit, the surface roughness starts to deteriorate plastically; Burnishing with smaller roller contact width $(1 \mathrm{~mm})$ is 
capable of improving the surface roughness up to $40 \%$. Burnishing speed $110 \mathrm{rpm}$ yields the highest improvement in hardness, as much as $30 \%$ increase.

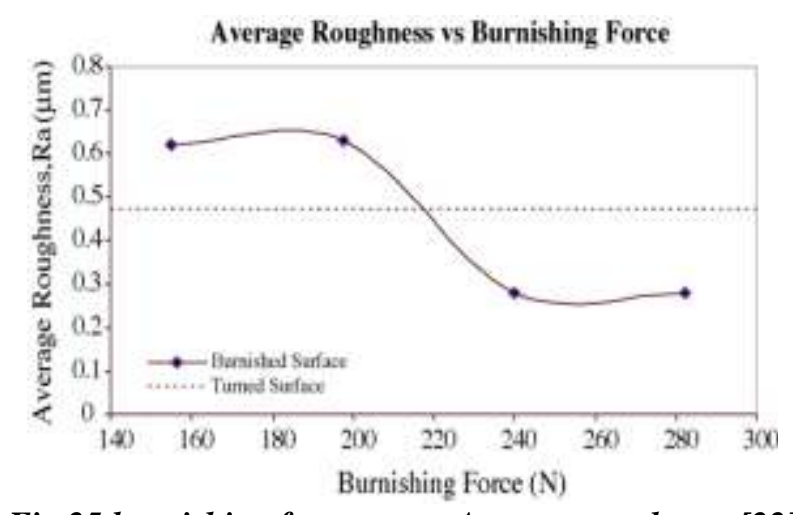

Fig.25 burnishing force verses Average roughness [22]

Increasing burnishing force has a negative impact on the wear resistance of burnished Aluminum 6061 surfaces. [22]

\subsection{Aluminum alloy}

Aysus Sagbas worked on Analysis and optimization of surface roughness in the ball burnishing process using response surface methodology and desirability function. Based on his work it was predicted that the surface roughness reduces with increasing burnishing force and no. of tool passes.

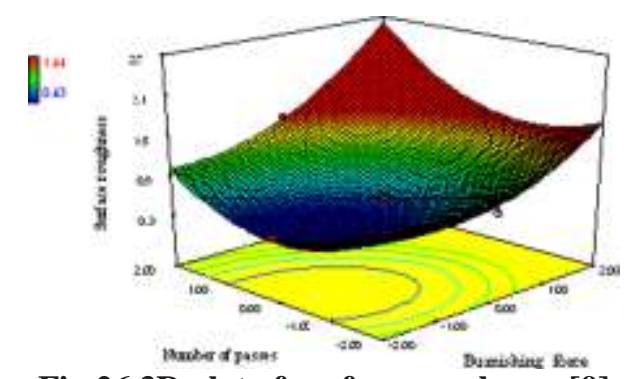

Fig.26 3D plot of surface roughness [9]

Fig. 26 shows 3D plot of surface roughness with respect to burnishing force and no. of burnishing tool passes. The red region shows higher roughness value while blue region shows lower roughness value.

\subsection{C3605 Brass}

N.S.M. EL-Tayeb et al worked on Prediction of burnishing surface integrity using Radial Basis Function. Based on their work a radial basic function algorithm was successfully used to predict the surface roughness for burnishing brass surface. [12]

Highest reduction in $\mathrm{Ra}(200 \%)$ was achieved at lower burnishing speeds. Increasing both burnishing speed and depth showed a negative impact on improvement of surface roughness especially at higher feed rate. $50 \%$ improvement in the hardness of burnishing surfaces was achieved at lower feed rate.

\section{Conclusion}

- Burnishing force and number of burnishing tool passes are the important parameters to improve the ductility of materials.

- Burnishing process greatly affects the frictional coefficient and improves wear resistance of materials.

- Different methods can be used effectively for obtaining optimum parameters for burnishing process.

- Depth of penetration, feed rate, and burnishing speed are also play an important role to improve material properties.

- Tribological aspects like appropriate lubricants for obtaining better surface quality are selected.

- Optimum burnishing parameters gives the lowest value for surface roughness and thus surface finish improved.

- Hardness is improved by burnishing process by selecting optimum process parameters. 
- Finite element analysis is another way for obtaining the simulated results for residual stresses and surface roughness that can be compared with experimental values.

- 3D FEA for burnishing process can give the simulated result for roughness and residual stresses.

- Fatigue strength improvement for non ferrous metals and alloys materials like aluminum and aluminum alloys can be investigated which can play an important role in aerospace and industrial applications.

- Wear resistance can be improved after burnishing process.

- As compared with other surface finishing processes burnishing can give better surface quality and dimensional accuracy.

\section{References:}

[1] Adel Mahmood Hassan, "The effect of ball and roller burnishing on the surface roughness and hardness of some non ferrous metal", Jordan Uni6ersity of Science and Technology, Irbid, Jordan, PP-385-391, 1997

[2] Fang Jung Shiou, Chien-Hua Chen, "Freeform surface finish of plastic injection mold by using ball burnishing process", National Taiwan University of Science and Technology, Taipei, Taiwan, PP-248-254,2003.

[3] U. M. Shirsat, B. B. Ahuja, "Parametric Analysis of combined turning and ball burnishing process", International journal of engineering and material science, Vol. 11, PP-391-396, 2004

[4] H. Hamadache, L. Laouar, N. E. Zeghib, K. Chaoui, "Characteristics of Rb40 steel superficial layer under ball and roller burnishing", Journal of Materials Processing Technology, Algeria, PP-130-136, 2006.

[5] L.N. Lopez De Lacalle, A. Lamikiz. ,J. A. Sánchez, J. L. Arana, “The effect of ball burnishing on heat treated steel and inconel 718 milled surface", Int J Adv Manuf Technol, PP-958-968, 2007.

[6] Prafulla Chaudhari, GK Awari and SS Khandare, "Investigation On micro and Macro properties of ball burnished component", VSRD-TNTJ, Vol. 2 (3),PP- 137-143, 2011.

[7] A.S. Maheshwari, U.M. Shirsat, "Optimization of Two ball burnishing process parameters to improve material properties", S.V. National Institute of Technology, Surat - 395 007, Gujarat, India, PP-531-535, 2011.

[8] F.Gharbi, S. Sghaier, K. J. Al Fadhalah, and T. Benameur, "Effect of ball burnishing process on the surface quality and microstructure properties of AISI 1010 steel plates", JMEPEG, Volume 20(6), 2011.

[9] Aysus Sagbas, "Analysis and optimization of surface roughness in the ball burnishing process using response surface methodology and desirability function", Mersin University, Tarsus Technical Education Faculty, Department of Mechanical Education, 33400 Tarsus-Mersin, Turkey, PP-992-998, 2011.

[10] J.N. Malleswara Rao, A. Chenna Kesava Reddy and P.V. Rama Rao, "Evaluation of optimum values of surface roughness on Al work piece using roller burnishing", International Journal of Engineering Research and Technology, ISSN 0974-3154 Volume 4, PP293-303, 2011.

[11] J.N. Malleswara Rao, A. Chenna Kesava Reddy, P.V. Rama Rao B. Mayuri, "Finite element Approach for the prediction of residual stresses in aluminum work piece produced by roller burnishing", International Journal of Design and Manufacturing Technology (IJDMT), ISSN 0976 - 6995, PP- 07-20,2011.

[12] N.S.M.EL-Tayeb,S. Purushothaman, "Prediction of burnishing surface integrity using Radial Basis Function", International Journal of Mechanical and Materials Engineering (IJMME), Vol.6, PP-391-399, 2011.

[13] Dabeer, P.S. \& Purohit, G. K., "Effect of ball burnishing parameters on Surface roughness using surface roughness Methodology", APEM journal, ISSN-1854-6250,PP-111-116,2010.

[14] W Bouzid Sai, K.Sai, "Finite element modeling of burnishing of AISI 1042 steel", Int J Adv Manuf Technol, 460-465, 2005

[15] Fathi Gharbi, Salem Sghaier \& Hedi Hamdi \& Tarek Benameur, "Ductility improvement of aluminum 1050A rolled sheet by a newly designed ball burnishing tool device", J Adv Manuf Technol, PP-87-99, 2012

[16] M. Sayahi, S. Sghaier \& H. Belhadjsalah, "Finite element analysis of ball burnishing process: comparisons between numerical results and experiments", J Adv Manuf Technol, 2012.

[17] Ugur Esme, "Use of grey based taguchi method in ball Burnishing process for the optimization of Surface roughness and micro hardness of AA 7075 aluminum alloy", MTAEC9, 44(3),ISSN-1580-2949, PP-129-135, 2012.

[18] S. Kwofie, "Description and simulation of cyclic stress-strain response during residual stress relaxation under cyclic load", ICM11, PP-293-298, 2011.

[19] Khalid S. Rababa, Mayas Mohammad Al mahasne, "Effect of roller burnishing on mechanical behavior and surface quality of $\mathrm{O}_{1}$ Alloy steel, Research Journal of Applied Sciences, Engineering and Technology 3(3): 227-233, ISSN: 2040-7467, PP-227-233, 2011

[20] Malleswara Rao J. N., Rama Rao P.V., "The effect of roller burnishing on surface hardness and surface roughness on mild steel specimen”, International Journal Of Applied Engineering Research, Dindigul Volume 1, No 4,ISSN-0976-4259, PP-777-785, 2011.

[21] K. O. Low, L. K. Wong, "Tribological effect of polymer surface modification through plastic deformation”, Bull. Mater. Sci., Vol. 34, No. 7, PP-1549-1555, 2011.

[22] N.S.M. El Tayeb, K.O. Low, P.V. Brevern, "Influence of roller burnishing contact width and burnishing orientation on surface quality and triblogical behavior of Aluminum 6061", Faculty of Engineering and Technology, Multimedia University, 75450 Melaka, Malaysia, PP-272-278,2007. 